\title{
Adaptability and Awareness of Augmented Reality in Teacher Education
}

\author{
Maruti Kumar Tripathy ${ }^{1 *}$ and Bhujendra Nath Panda ${ }^{2}$
}

${ }^{1}$ Research Scholar and ${ }^{2}$ Professor \& Dean of Research

Department of Education, Regional Institute of Education, Bhubaneswar, Odisha, India

"Corresponding author: maruti.tripathy@yahoo.com

Received: $22-05-2021$

Revised: 24-07-2021

Accepted: 11-08-2021

\begin{abstract}
As an emerging technology, Augmented Reality has a huge potential for the educational field. Teacher education is the root of all other professions so the current study was intended to explore the resources available in the teacher education institute and the awareness about augmented reality among the teacher educators and pre-service teachers. The data was collected by two self-developed questionnaires i.e. Resources Availability and Awareness Questionnaire for Pre-Service Teacher \& Resources Availability and Awareness Questionnaire for Teacher Educator, the result revealed that the teacher education institutes of Odisha and the TEs \& PSTs have adequate resources to use augmented reality in the classroom but the awareness level among them found to be very low.
\end{abstract}

Keywords: augmented reality (AR), teacher educators (TE), \& pre-service teachers (PST), adoptability, awareness

Teaching is the one profession that creates all other professions. A good teacher can inspire, hope, ignite the imagination, and install a love of learning.

- Brad Henry

Over the past few years, the dimension of learning has changed so far. The definition of being educated is now replaced with more comprehensive terms such as being a skilled professional. The professionals of educational field are now striving to provide real life experience to students by shifting the classroom beyond the four walls. It is not always possible to provide real life experiences and first hand exposure of various practical aspects of education especially in the field of STEM. Some of the science activities are very risky to conduct in a classroom and even unethical. Students' interest to choose science as discipline is decreasing day by day; they find the subjects to be abstract and complex (Saidin, et al. 2015) but with the emergence of immersive technologies such as virtual reality, augmented reality \& mixed reality it is now possible to do impossible things in the classroom. Among the immersive technologies, $42 \%$ of consumers adopted
Augmented Reality (AR) over the last 12 months, making it the most emerging technology in the field of medicine, education and industry over the world (Perkins Coie LLP, et al. 2020). Marker based AR and mobile based AR (MAR) have been chosen widely for the education purpose during the COVID-19 pandemic (Sirkaya \& Sirkaya, 2020; Vuta, 2020).

Augmented reality (AR) has vast application in educational sector; it has potential to offer seamless interaction between the real and the virtual world (Birt \& Vasilevski, 2021; Ghare et al. 2017; Kesim \& Ozarslan, 2012) also increase peer interaction (Patel \& Panchotiya, 2020). AR technology in the classroom has potential to improve and promote learning

How to cite this article: Tripathy, M.K. and Panda, B.N. (2021) Adaptability and Awareness of Augmented Reality in Teacher Education. Educational Quest: An Int. J. Edu. Appl. Soc. Sci., 12(2): 107-114.

Source of Support: None; Conflict of Interest: None (9) क्व 
abilities, motivation, problem-solving abilities and learning achievement among students (Vuta, 2020; Lafargue, 2018). It could be employed to promote self directed learning, problem solving skills, \& self motivation among students (Renner, 2014; Wu et al. 2013) and it promote interest to learn (Petrov \& Atanasova, 2020; Celik et al. 2020; Piovesan et al. 2012). Although AR technologies are very promising in the STEM fields but need improvement and experiments in social science context (Radianti et al. 2020). Various advantages of AR in educational field were, it improve academic gain, the retention of learning extended to a longer period of time and students feel like motivated to learn through AR applications (Garzon et al. 2019).

\section{Augmented Reality}

Augmented Reality (AR) is an immersive technology which allows the users to superimpose a digital content such as 3D images, texts, video and sound over a real object or real world environment. The earliest version of augmented reality was designed to provide an immersive mixed reality experience. It emerged in the early 1900s and the term "Augmented Reality" was coined by P Caudell. There are various type of AR used all over the world, these are

1. Projection based Augmented Reality: As per the name the projection based AR projects the virtual image into the real world for superimposition. For example: digital keyboard on the desk.

2. Recognition based Augmented Reality or Marker based Augmented Reality: It is the most famous type of AR which allows the users to scan an image or a mark and the preinstalled come to live. Once the marker image is scanned with a smart phone it is replaced with a corresponding image that is prefixed earlier.

3. Location based Augmented Reality: In the smart devices, location based AR uses the GPS, accelerometer \& compass features to enhance the experience of map. It is mostly integrated with Google map to show some interesting information about the map.

4. Superimposition Augmented Reality: It is most popular among gamers. This type of AR replaces the entire object or a part of it with the augmented reality contents, mostly used in FPS games.

\section{Teacher \& Augmented Reality}

Teachers are the creators of society, they make the future generation as various professionals. As we know, knowledge is never fixed, it is evolving over time. So it is important to install the learning abilities such as exploration, investigation, experiment and discovery among learners. As a teacher, it is not always possible to provide real life experience in every context of the educational field; but with the emergence of augmented reality, it is now possible. It is now easy to create AR contents and handle augmented reality applications for education and entertainment purposes by using simple smart phones (Vuta, 2020) \& augmented reality applications have high levels of personalization capacity (Petrov \& Atanasova, 2020).

\section{Review of Related Literature}

Various literatures related to Augmented Reality reviewed in light of the education and learning field. The summary of the reviews was mentioned below.

Evolution: The trends of research on immersive technology increase sharply until 2017 and become steady till the end of 2018, but in the educational area the trend is still moving upward (Garzon et al. 2019; Muñoz-Saavedra et al. 2019). Equipment sales, in-app purchase, product placement and advertising increased significantly over the years in the field of AR (Perkins Coie LLP et al. 2020).

Potential for Education: AR technology in classroom has potential to improve and promote learning abilities, motivation, problem-solving abilities and learning achievement among students (Vuta, 2020; Lafargue, 2018) also promotes the motivation level of pre-service teachers (Petrov \& Atanasova, 2020; Khan et al. 2019). Most of the elementary teachers used AR applications in Kuwait due to it motivating and engaging students in classroom activities (Almoosa, 2018) even it also promotes intrinsic motivation among learners (Hanatono et al. 2018). AR applications decrease task completion time and error rate hence reduce mental workload (Jeffri \& Rambli, 2021).

Usability: It is easy to create AR contents by using simple smart phones (Vuta, 2020) \& have a 
high level of personalization capacity (Petrov \& Atanasova, 2020).

Challenges: AR is not effective for overcrowded classrooms (Liano et al. 2020). Many of the users reported being frustrated while using AR tools outdoors (Saidin et al. 2015). The main problem of adopting immersive technology was its cost of equipment (Holly et al. 2021; Rehman-Shams, 2019).

Attitude and Acceptance: Pre-Service teachers were intending to use immersive technology in their classrooms and they desired more professional development in this field (Eutsler \& Long, 2021). $10^{\text {th }}$ and $12^{\text {th }}$ grade students have a positive attitude towards AR applications, and it increases their learning achievements (Harun et al. 2019). The student teachers reported that, Immersive technology such as VR can be a good way of teaching due to its flexibility in approach, high degree of interaction with the real and virtual world and risk free usability (Holly et al. 2021).

\section{Rationale of the Study}

Teaching is always a challenging task. Teachers need to be up-to-date with the current knowledge and information, and need to induce various teaching strategies to be successful in the teaching field. Teacher education programmes encompass teacher training, increase competencies and empower the teachers to deal with the current educational demands. However, due to tremendous development of the technological field and future demand of students, technology is considered a very important part of teacher education as well as in the professional life of a teacher.

Various studies have been conducted across the world on teacher education with reference to immersive technology. From the reviews, it was found that augmented reality has huge potential for development of education. It can provide real life experience in a safe way and promote problem solving ability, retention of learning and motivation to learn among students. It was also found that creating such contents is very handy and easy. It is very popular among student teachers as it reduces workload and provides seamless interaction between the real and the virtual world. However some studies resulted negatively such as, there are very minimal applications of AR available for special need users (Garzon et al. 2019). It promotes cognitive overload among learners and teachers can not add \& modify learning contents in AR applications (Hanatono et al. 2018). AR enabled classrooms were not as effective as traditional classroom instruction (Renner, 2014). Almost all the teacher participants (95\%) Saudi Arabia agreed that school doesn't have adequate ICT infrastructure for implementation of immersive technology \& about $3 / 4$ no of participants don't have appropriate IT skills to use AR applications in school (Alkhattabi, 2017).

However, there is no study conducted on resources availability among the TEs, PSTs and teacher education institute in India to effectively use AR applications and no study has covered assessing the awareness level of teacher educators and student teachers with reference to augmented reality. With such contradictory review findings and research gaps, it is a pertinent question before the investigator to explore the concern area.

\section{Research Question}

1. What are the resources available in teacher education institutions for successful implementation of Augmented Reality in Classroom?

2. Do the teacher educators have adequate resources to use Augmented Reality and its applications in the teaching process?

3. Do the pre-service teachers have adequate resources to use Augmented Reality and its applications in the teaching and learning process?

4. Do teacher educators are aware about Augmented Reality and its applications?

5. Do pre-service teachers are aware about Augmented Reality and its applications?

6. Do teacher educators and pre-service teachers are competent enough to use Augmented Reality for teaching and learning?

\section{Objectives of the Study}

1. To find out the resources available in the teacher education institutes for effective use of the Augmented Reality technology and its application.

2. To find out the resources available among teacher educators to use the Augmented 
Reality technology and its application in their teaching effectively.

3. To explore the current practices of teacher educators and pre-service teachers in the educational field in terms of use of technology.

4. To find out resources available among preservice teachers to use Augmented Reality technology and its application in their teaching and learning process.

5. To explore the level of awareness and application about the technology of Augmented Reality among teacher educators and pre-service teachers.

\section{Statement of the Problem}

In the present study the researcher was interested in exploring the resources available among the teacher educators and pre-service teachers. The intention was to find out the awareness level of application of Augmented Reality in the educational field. Thus the study was entitled as, "Adaptability and Awareness about Augmented Reality in Teacher Education."

\section{Method}

Exploratory research design was used for this present research, and survey method was used to collect the data.

\section{Population and Sample of the Study}

The population of the study was teacher educators and pre-service teachers of teacher education institutions of Odisha, i.e., both 2-year and 4-year integrated B.Ed students and the Teacher Educators who were assigned to teach them. The sample of the study consisted of 21 educators and 216 pre-service teachers from various teacher education institutes of Odisha and the sample was selected by using the voluntary response sampling technique.

\section{Tools Used for the Present Study}

The researcher developed questionnaire as tool for the present research which were:

1. Resources Availability and Awareness Questionnaire for Pre-Service Teacher.

2. Resources Availability and Awareness Questionnaire for Teacher Educator.

\section{Analysis and Interpretation of the Data.}

\section{Availability of Resources in Teacher Education Institutes}

Responses of teacher educators and pre-service teachers regarding resources available in teacher education institutes were presented in Table 1.

Table 1: Resources Available in Teacher Education Institutes

\begin{tabular}{lll}
\hline Resources & TEs (N=21) & PSTs (N=216) \\
\hline A computer lab & $20(95.2 \%)$ & $165(76.4 \%)$ \\
Broadband connectivity & $4(19 \%)$ & $12(5.6 \%)$ \\
Wi-Fi connectivity & $12(57.1 \%)$ & $64(29.6 \%)$ \\
Projector in Classroom & $13(61.9 \%)$ & $161(74.5 \%)$ \\
Smart board in Classroom & $9(42.9 \%)$ & $64(29.9 \%)$ \\
Speaker \& Microphone & $13(61.9 \%)$ & $102(47.2 \%)$ \\
Web Camera facility & $6(28.6 \%)$ & $39(18.1 \%)$ \\
E- Library or & - & $145(77.1 \%)$ \\
E-respiratory & & \\
\hline
\end{tabular}

From the Table 1, it was found that, 95\% TE and $76.4 \%$ of PST said that they have a computer lab, $57.1 \%$ TE \& $29.6 \%$ argued that they have Wi-Fi connectivity, $61.9 \%$ TE \& $74.5 \%$ PST said that they have projectors in the classroom, $42.9 \%$ TE \& $29.9 \%$ PST said that they have smart board in the classroom and $77.1 \%$ PST said that they have an E-library in their institution.

\section{Availability of Resources among Teacher Educators and Pre-Service Teachers}

Responses of TEs \& PSTs regarding resources available among them were collected and presented in Table 2.

Table 2: Resources Available among Teacher Educators and Pre-Service Teachers

\begin{tabular}{lll}
\hline Resources & TEs (N=21) & PSTs (N=216) \\
\hline Laptop & $17(81 \%)$ & $100(46.3 \%)$ \\
Desktop & $1(4.8 \%)$ & $17(7.9 \%)$ \\
Broadband/ Wi-Fi & $9(42.9 \%)$ & $36(16.7 \%)$ \\
Smart Phone & $21(100 \%)$ & $213(98.6 \%)$ \\
Modem & $1(4.8 \%)$ & $5(2.3 \%)$ \\
Mobile Data & $19(90.5 \%)$ & $208(96.3 \%)$ \\
\hline
\end{tabular}

From the table 2, it was found that $81 \%$ of TE has a portable laptop, $4.8 \%$ of them have a desktop and $42.9 \%$ of them used broadband/ Wi-Fi, $90.5 \%$ used 
mobile data \& $4.8 \%$ used modem for communication, all the teacher educators have a smart phone.

From the table it was also found that $81 \%$ of PSTs have a portable laptop, $4.8 \%$ of them have a desktop and $42.9 \%$ of them used broadband/ Wi-Fi, 90.5\% used mobile data \& $4.8 \%$ used modem for communication, $98.6 \%$ of them have a smart phone.

\section{Teaching and Learning Online}

Table 3: Methods of Assessment used by Teacher Educators to Assess Growth of Pre-service Teachers

\begin{tabular}{lll}
\hline Method of Assessment & TEs (N=20*) & PSTs (N=216) \\
\hline E assessment & $9(45 \%)$ & $98(45.4 \%)$ \\
E-presentation & $17(85 \%)$ & $84(38.9 \%)$ \\
Portfolio & $3(15 \%)$ & $25(11.6 \%)$ \\
Project & $6(30 \%)$ & $74(34.3 \%)$ \\
Offline test & $2(10 \%)$ & $133(61.6 \%)$ \\
No assessment & $1(5 \%)$ & $9(4.2 \%)$ \\
\hline
\end{tabular}

*As 1 TE mentioned that helshe had not take any classes in online mode during theCOVID-19 pandemic, he/she was excluded from the calculation.

\section{Teacher Educators}

Out of 21 TEs, 20 (95.2\%) TEs were teaching their students through online media during lockdown.

$25 \%$ of TEs mentioned all of their students, $55 \%$ mentioned that most of their students \& $20 \%$ mentioned that some of their students have adequate devices to attend online classes.

$10 \%$ of TEs mentioned all of their students, $60 \%$ mentioned that most of their students \& 30\% mentioned that some of their students have adequate internet connection to attend online classes.

5\% TEs mentioned that all of their students interact with them while teaching, while $70 \%$ said most and $25 \%$ said some of their students interact with them while teaching online.

$5 \%$ of TEs mentioned that all of their students were asking questions for clearing the doubt, while $55 \%$ said most \& $20 \%$ some of their students were asking questions for clearing the doubt during the online classes.

All the TEs used Google meet platform for teaching purposes while $25 \%$ used Zoom app
\& $10 \%$ used other platforms to teach students online.

$45 \%$ TEs mentioned that they used E-assessment tools for Assessing students, while 85\% mentioned E-presentation, 15\% mentioned Portfolio, 30\% mentioned project, \& 10\% mentioned offline tests they used to assess the students progress. 5\% TEs said that they are not assessing the student growth during the lockdown.

\section{Pre-Service Teachers}

Out of 213 (98.6\%) PSTs; 37.6\% (80 No.) used the same mobile over 3 year of time, $24.9 \%$ of them used for $2-3$ years, $22.5 \%$ of them used for 1-2 years and $15 \%$ of them buy a new mobile recently.

$72.7 \%$ of PSTs had teaching experience; $68.6 \%$ got the experience during internship, $11.1 \%$ in formal school and $27.3 \%$ of them had no teaching experience.

$0.9 \%$ of the PSTs spend less than 1 hour on internet, $21.8 \%$ of them spend $1-3$ hour daily, $32.4 \%$ spend $3-5$ hours daily, $23.6 \%$ spend $5-8$ hours daily, $11.1 \%$ spend $8-10$ daily, $10.2 \%$ of the PSTs spend more than 10 hours daily on internet.

$\square$ The $\%$ of use of online meeting applications by PSTs as: Google meet 92.6\%, Zoom 44.4, Microsoft team $2.8 \%$, other $11.6 \%$.

$\square$ For self learning purposes $64.4 \%$ of PSTs prefer to use their own books, $40.3 \%$ prefer library, $25.5 \%$ prefer e-library, $63.4 \%$ prefer Google search, and $51.4 \%$ prefer online learning apps.

$\square$ For clearing any academic doubts, $12.5 \%$ of PSTs contact the concerned educators over mail, $40.3 \%$ of them over voice call, $32.9 \%$ over text message, $48.1 \%$ over Whatsapp, $78.2 \%$ of them during online classes and $3.7 \%$ of the PSTs prefer not to contact.

$\square$ While preparing the assignment $69.4 \%$ of the PSTs prefer books, $81.5 \%$ prefer searching online, $58.3 \%$ prefer to discuss with peers to complete the task.

$64.4 \%$ of PSTs mentioned that their educators used the Lecture method during teaching online, $73.6 \%$ mentioned the Discussion method, $33.8 \%$ 
mentioned the Demonstration method, 35.6\% mentioned the Narration method, and 9,7\% said that their educators used other methods while teaching online. $88 \%$ of PSTs (190 no.) mentioned that online teaching is not adequate to learn effectively.

\section{Problem faced by Teacher Educators E Pre-Service Teachers}

Responds from both the TEs and PSTs related to problem faced during online classes mentioned in the Table 4.

Table 4: Problem faced by Teacher Educators \& Preservice Teachers while Online Classes

\begin{tabular}{lll}
\hline Problem Faced & TEs (N=20) & PSTs (N=216) \\
\hline Connection issues & $15(75 \%)$ & $164(75.9 \%)$ \\
No or Less interaction & $6(30 \%)$ & $121(56 \%)$ \\
Resources Unavailable & $2(10 \%)$ & $52(24.1 \%)$ \\
Teacher centric approach & $8(40 \%)$ & $92(42.6 \%)$ \\
Assessment issues & $4(20 \%)$ & $95(44 \%)$ \\
No scope for doubt clearing & $1(5 \%)$ & $30(13.9 \%)$ \\
Low attendance & $1(5 \%)$ & - \\
Less no of classes & $1(5 \%)$ & - \\
\hline
\end{tabular}

From the Table 4 it was found that both the TEs and PSTs faced various problems during online classes these are; $75 \%$ TEs \& $75.9 \%$ PSTs mentioned that they face connection issues during online classes, $30 \%$ TEs \& $56 \%$ PSTs mentioned that less or no interaction with peers and educators, $10 \%$ TEs \& $24.1 \%$ PSTs mentioned that they don't have the adequate resources, $40 \%$ TEs mentioned that they forced to choose teacher centric approach \& $42.6 \%$ PSTs mentioned that teacher centric approach was not sufficient for learning, $20 \%$ TEs \& $44 \%$ PSTs mentioned that they face problem while assessment, $5 \%$ TEs \& $13.9 \%$ PSTs mentioned other issues such as limited scope for clearing the doubt, and less no of classes they have provided.

\section{Awareness of Teacher Educators E Pre-Service Teachers about Augmented Reality}

The concerned data collected and presented in Table 5.

From the table 5, it was found that:

TEs (21 no.) had scored as mean 2.90 and SD 1.95 in terms of knowing about AR, (in which maximum score possible was 7 ). $\square$ TEs (21 no.) had scored as mean 2.90 and SD 1.95 , in terms of using AR directly or indirectly in various fields such as taking photos, (in which max score possible was 7).

$\square$ TEs (21 no.) had scored as mean 2.43 and SD 0.87 , in terms of intention to use in teaching and other fields, (in which maximum score possible was 3).

Table 5: Awareness of Teacher Educators \& Preservice Teachers about Augmented Reality

\begin{tabular}{llllllllll}
\hline & \multicolumn{2}{l}{$\begin{array}{l}\text { Awareness } \\
\text { (Range 0 to 7) }\end{array}$} & \multicolumn{3}{l}{$\begin{array}{l}\text { Using (Range } \\
\text { 0-7 for TE, 0-8 } \\
\text { for PST) }\end{array}$} & \multicolumn{4}{l}{$\begin{array}{l}\text { Intention to Use } \\
\text { (Range 0-3) }\end{array}$} \\
\cline { 2 - 10 } & $\mathbf{N}$ & $\mathbf{M}$ & SD & N & M & SD & N & M & SD \\
\hline TE & 21 & 2.90 & 1.95 & 21 & 2.90 & 2.26 & 21 & 2.43 & 0.87 \\
PST & 216 & 4.56 & 1.98 & 157 & 4.27 & 2.50 & 216 & 2.40 & 096 \\
\hline
\end{tabular}

$\square$ PSTs (216 no.) had scored as mean 4.56 and SD 1.98 in terms of knowing about AR, (in which maximum score possible was 7 ).

PSTs (157** no.) had scored as mean 4.27 and SD 2.50 , in terms of using AR directly or indirectly in various fields such as taking photos, (in which max score possible was 8 ).

$\square$ PSTs (216 no.) had scored as mean 2.40 and SD 0.96 , in terms of intention to use in teaching and other field, (in which maximum score possible was 3).

**as 57 PSTs mentioned that they have no teaching experience, they were excluded from the calculation of USE domain of AR.

\section{RESULTS AND DISCUSSION}

Most of the teacher education institutes have adequate resources for implementation of augmented reality applications in the classroom. The result was differ from the findings of the study Alkhattabi (2017), as it mentioned most of the institutions does not have adequate equipments to implement $\mathrm{AR}$ in classroom

$\checkmark$ All the teacher educators have smart phones and internet connections which were sufficient for implementation of AR in the classroom. The finding contrasted by the result of the study Alkhattabi, 2017, as it mentioned $3 / 4$ of the educators does not have adequate resources.

$\square$ TEs used various platforms (100\% used Google meet, $25 \%$ used Zoom \& 10\% used other 
platforms) to teach their students and they mostly assessed their students by online assessment tools (85\% used E-presentation, $15 \%$ used portfolio and $45 \%$ used E-assessment techniques).

98.6\% of PSTs have smart mobile devices and $46.3 \%$ of them have portable laptops and most of them have an adequate internet connection, which was adequate for implementation of AR in the classroom. This finding was in contrast with Garzon et al. (2019), as it found that students have very minimal tools to use AR. $37.6 \%$ of PSTs mentioned that they used the same smartphone for over 3 years, which may not support the latest AR applications.

$\square$ Most of the PSTs mentioned that they spend 1-5 hours daily on the internet for browsing social media, self-study, assignment and entertainment purposes.

$\square$ Although $73.6 \%$ TEs used discussion methods for teaching, most of the PSTs (88\%) teachers mentioned that online teaching is not sufficient for learning.

The major problems faced by both TEs and PSTs were connection issues $(75 \%$ \& $75.9 \%$ respectively or respectively for TEs \& PSTs) and problems with interaction with peers and educators (30\% \& 56\% respectively for TEs \& PSTs).

Most of the teacher educators does not well aware about AR and its applications $(M=2.90$ $\& S D=1.95)$ but they somehow used the AR applications in life during taking photos etc. the TEs have positive attitude towards AR \& its applications, most of them are interested to learn about $A R$ and to use in their classroom $(\mathrm{M}=2.43 \& \mathrm{SD}=0.87)$. The findings were supported by Wu, et al. (2013); Eutsler \& Long, (2021); \& Holly et al. (2021), but it differed from the findings of Alkhattabi, 2017; as it resulted in teachers being very restricted to change and use AR in their teaching practice.

PSTs were more aware about AR \& its applications than TEs, but the score was still low $(M=4.56 \& S D=1.98)$. They used $A R$ in various fields such as in taking photos and in teaching their students; but the score was just above the mean value which is not very high $(\mathrm{M}=4.27 \& \mathrm{SD}=2.50)$. PSTs also have a positiveattitude towards AR\& its applications, most of them are interested to learn about AR and to use it in their classroom $(M=2.40 \&$ $\mathrm{SD}=0.96)$. the findings was supported by the studies Holly et al. (2021); Radianti et al. (2020); \& Almoosa (2018); but the result slightly differ from the findings of the study Raber, 2020; as it found that motivation to use AR decreased \& Saidin et al. (2015) reported that most of the participants reported being frustrated after using AR.

\section{Educational Implication}

The result of the study revealed that teacher education instructions, TEs and PSTs have adequate resources to use Augmented Reality in teaching and learning purposes but awareness level among them was very poor. The study will help the participants to explore AR and its potential in education. The study will also help them frame various activities, workshops on AR uses and application. The study will surely help the concerned authority to take care of this area for technological advancement in teacher education institutions.

\section{Suggestion for Further Research}

The present study has certain limitations and augmented reality has a wide area of study so various suggestions regarding the future study.

1. Future study can be extended to various other educational areas such as school education \& technical education, and a large sample can be taken for better generalization.

2. Various other dimensions such as mental workload, teaching experience, socio economic status and various disciplines can be integrated in the AR study for a comprehensive picture.

3. Further influence, opportunity, challenges \& potential of AR and its Application can be explored in future research.

\section{REFERENCES}

Alkhattabi, M. 2017. Augmented Reality as E-learning Tool in Primary Schools' Education: Barriers to Teachers' Adoption. iJET, 12(2).

Almoosa, A.S. 2018. A Qualitative Case Study in Augmented Reality Applications in Education: Dimensions of 
Strategic Implementation. Dissertations, University of Northern Colorado, 485. htts://digscholarship.unco.edu/ dissertations/485

Birt, J. and Vasilevski, N. 2021. Comparison of Single and Multiuser Immersive Mobile Virtual Reality Usability in Construction Education. Educational Technology E Society, 24(2): 93-106.

Celik, C., Guven, G. and Cakir, N.K. 2020. Integration of mobile augmented reality (MAR) applications into biology laboratory: Anatomic structure of the heart. Research in Learning Technology, 28: 2355.

Eutsler, L. and Long, C.S. 2021. Preservice Teachers' Acceptance of Virtual Reality to Plan Science Instruction. Educational Technology E Society, 24(2): 28-43.

Garzón, J., Pavón, J. and Baldiris, S. 2019. Systematic review and meta-analysis of augmented reality in educational settings. Virtual Reality, 23: 447-459. https://doi.org/10.1007/s10055-019-00379-9

Ghare, A.M., Khan, M.A., Rangwala, M., Kazi, S., Panwala, S. and Salam, A. 2017. Augmented Reality for Educational Enhancement. International Journal of Advanced Research in Computer and Communication Engineering, 6(3): 232-235.

Hantono, B.S., Nugroho, L.E. and Santosa, P.I. 2018. MetaReview of Augmented Reality in Education. Conference Paper, July 2018. DOI: 10.1109/ICITEED.2018.8534888, https://www.researchgate.net/publication/328992100

Harun., Tuli, N. and Mantri, A. 2019. Experience Fleming's rule in Electromagnetism Using Augmented Reality: Analyzing Impact on Students Learning. Procedia Computer Science, 172: 660-668.

Holly, M., Pirker, J., Resch, S., Brettschuh, S. and Christian, G. 2021. Designing VR Experiences - Expectations for Teaching and Learning in VR. Educational Technology $\mathcal{E}$ Society, 24(2): 107-119.

Jeffri, N.F.S. and Rambli, D.R.A. 2021. A review of augmented reality systems and their effects on mental workload and task performance. Heliyon, 7: e06277.

Kesim, M. and Ozarslan, Y. 2012. Augmented reality in education: current technologies and the potential for education. Procedia - Social and Behavioral Sciences, 47: $297-302$.

Khan, T., Johnston, K. and Ophoff, J. 2019. The Impact of an Augmented Reality Application on Learning Motivation of Students. Hindawi Advances in HumanComputer Interaction, 2019, Article 7208494. https:/doi. org $/ 10.1155 / 2019 / 7208494$

Lafargue, D. 2018. The Influence of Mixed Reality Learning Environments in Higher Education STEM Programs: A Study of Student Perceptions of Mixed Reality SelfEfficacy, Engagement, and Motivation Using Augmented and Virtual Reality. Dissertation, University of Louisiana, Lafayette, 2018. ProQuest 10932912.
Liano, R.A., Amanda, N., Pratiwi, A. and Gumawan, A.S. 2020. A Systematic Literature Review: Learning with Visual by The Help of Augmented Reality Helps Students Learn Better. Procedia Computer Science, 179: 144-152.

Muñoz-Saavedra, L., Miró-Amarante, L. and DomínguezMorales, M. 2019. Augmented and Virtual Reality Evolution and Future Tendency. Applied Sciences, 10(332): 2020.

Patel, S. and Panchotiya, B. 2020. A Survey: Virtual, Augmented and Mixed Reality in Education. International Journal of Engineering Research E Technology (IJERT), 9(05).

Perkins Coie, L.L.P., XR Association and Boost, V.C. 2020. 2020 augmented and virtual reality survey report: Industry insights into the future of immersive technology, 4, 2020. Perkins Coie LLP, XR Association, Boost VC.

Petrov, P.D. and Atanasova, T.V. 2020. The Effect of Augmented Reality on Students' Learning Performance in Stem Education. Information, 11(209).

Piovesan, S.D., Passerino, L.M. and Pereira, A.S. 2012. Virtual reality as a tool in the education. IADIS International Conference on Cognition and Exploratory Learning in Digital Age (CELDA 2012), pp. 295-298.

Raber, J.A. 2020. Analysis of motivation, situational interest, and augmented reality. Dissertation, Kent State University College of Education, Health, and Human Services.

Radianti, J., Majchrzak, T.A., Fromm, J. and Wohlgenannt, I. 2020. A systematic review of immersive virtual reality applications for higher education: Design elements, lessons learned, and research agenda. Computers $\mathcal{E}$ Education, ELSEVIER, 147: 103778.

Rahman-Shams, S. 2019. The Effect of 3D Virtual Reality Technologies on Learning: A Qualitative Research. Dissertation, American College of Education. ProQuest 27912191.

Renner, J.C. 2014. Does Augmented Reality Affect High School Students' Learning Outcomes in Chemistry?. Dissertation, Grand Canyon University Phoenix, Arizona. UMI 3628589.

Saidin, N.F., Halim, N.A. and Yahaya, N. 2015. A Review of Research on Augmented Reality in Education: Advantages and Applications. International Education Studies, 8(12): 2015.

Sirakaya, M. and Sirakaya, D.A. 2018. Trends in Educational Augmented Reality Studies: A Systematic Review. Malaysian Online Journal of Educational Technology, 6(2): 60-74.

Vuță, D.R. 2020. Augmented reality technologies in education - a literature review. Bulletin of the Transilvania University of Braşov, Series V: Economic Sciences, 13(62).

Wu, H-K., Lee, S. W-Y., Chang, H-Y. and Liang, J-C. 2013. Current status, opportunities and challenges of augmented reality in education. Computers $\mathcal{E}$ Education, 62: 41-49. 